\title{
Promises that Matter: Reconfiguring Ecology in the Ecotrons
}

\author{
Celine Granjou \\ University Grenoble Alps, IRSTEA, France / Celine.granjou@irstea.fr \\ Jeremy Walker \\ University of Technology in Sydney, FASS, Australia / Jeremy.Walker@uts.edu.au
}

\begin{abstract}
Ecotrons are large instruments designed to produce experimentally valid knowledge through the controlled manipulation of enclosed, simplified ecosystems. Situating the ecotrons within a select genealogy of artificial biospheres, and drawing on interviews with key researchers engaged in the conception and recent construction of two ecotrons in France, we propose to think through ecotrons as promissory and anticipatory infrastructures that materialize a profound reconfiguration of ecologists' roles within wider civilizational narratives. Ecotrons encapsulate ecologists' ambitions to practice a 'hard' science, recognized by international environmental and science policy forums. They were integral to rise of the sub-discipline of functional ecology, which in turn underpins the policy discourse of 'ecosystem services'. Combining patterns of controlled experimentation with live simulations of future environmental conditions anticipated in climate change scenarios, the ecotron materialises a reorientation of the vocation of ecology: to secure the resilience of those 'ecosystem services' deemed critical to social life. Originally tasked with assessing the effects of biodiversity loss on the productivity and stability of the biosphere, ecotron research is increasingly focused on anthropogenic microbial ecosystems, and takes place within a terminology resolutely optimistic about the possibilities of microecological engineering, to the exclusion of earlier concerns with mass extinction.
\end{abstract}

Keywords: ecotrons, functional ecology, infrastructure, biodiversity, anticipation, global warming, ecosystem services

It is too late to dream ourselves back to a place under celestial domes whose interiors would permit domestic feelings of order... - Peter Slotjerdijk ${ }^{1}$

Ecologists have long struggled to affirm the scientific status and practical relevance of their discipline. Today, the imperative to meet the chal- lenges of societies' vulnerability to anthropogenic global change opens up new opportunities for ecologists to re-affirm the vital contribution of their discipline, which increasingly departs from norms of biodiversity conservation and nature protection to stress human well-being, development and survival in a warming world. The science and technology studies literature on anticipation 
in the life sciences has tended to focus upon biomedicine, nanotechnologies and synthetic biology. We suggest that closer attention to ecology is warranted. Manifest in its contemporary shift to the analysis of the minimum species composition of functioning ecosystems, we argue, is a reconfiguration of ecology into an anticipatory technoscience of civilizational security.

In this article we document this re-orientation of ecology's scientific and social missions through an analysis of recently-built research infrastructures called 'ecotrons'. Ecotrons are shared experimental facilities for research on the functional properties of ecosystems, designed to allow repeatable experimentation and hypothesis-testing in closed, artificial ecosystems where biological and environmental variables are subject to precise measurement, manipulation and control. We consider ecotrons as sites for the elaboration and re-alignment of narratives of justification, embodying promises that matter regarding the scientific status and social role of ecology. Ecological infrastructures and futures are co-produced in the same movement.

Two ecotrons have recently been built in France. One is located at Foljuif, near Paris, and there is another at Montpellier, associated with the Center for Evolutionary and Functional Ecology (CEFE). According to its website, the Montpellier ecotron "bridges the gap between the complexity of in natura studies and the simplicity of laboratory experiments". The word "ecotron" references the research machinery of the heroic age of experimental high-energy physics, the cyclotrons and 'atom smashers' of the 1930s and 1940s. The parallel is more than nominal. Ecotrons are the first ecological facilities sponsored by the Très Grandes Infrastructures de Recherche (TGIR) unit of the National Centre for Scientific Research (CNRS), which operates the 'very large research infrastructures' traditionally associated with subatomic and cosmological physics, such as synchrotrons, particle accelerators, and radio telescopes.

Our analysis develops a selective genealogy of the ecotron, tracing under-acknowledged influences that amount to a mutually constitutive history of 'functional' systems ecology and its experimental research infrastructures. We bring this history to bear on in-depth interviews conducted between 2009 and 2010, during the construction phase of the French ecotrons, when their potential impact on the discipline of ecology was a matter of anticipation as the first research projects were underway in the completed modules. ${ }^{2}$ We interviewed the designer and senior scientific manager of the Montpellier ecotron, as well as established researchers from laboratories in the cognate fields of systems ecology, plant physiology and microbial ecology. ${ }^{3}$ Most were enthusiastic about the new infrastructures and planned to utilise them in future research, although one ecologist, a forest specialist, was sceptical of claims that ecotrons would yield major advances. We have also drawn on institutional websites, and scientific literature presenting the results of ecotron-based research. Finally our results benefited from exchanges with ecologists who attended a restitution seminar where early versions of this research were presented. ${ }^{4}$

\section{I: State of the Art}

Our approach to ecotrons as promissory and anticipatory infrastructures draws upon recent work in the sociology of science and technology (STS), the history and philosophy of ecology, and critical security studies. Far from being given, taken for granted facilities, for STS scholars, research infrastructures represent collective achievements arising from specific political and historical contexts (Star \& Ruhleder, 1996). Assembling the machinery of knowledge production in itself requires significant research collaboration and coordination (Star \& Grisemer, 1989; Bowker \& Star, 1999; Edwards, 2010). Recent studies have focused on the backstage 'memory practices' of computer-driven data curation, including those of the Long-Term Ecological Research Network (LTER). Established in 1980, the LTER has since worked to standardise longperiod, site-based datasets across a wide range of representative 'natural biomes' or ecosystem types in order to enable analyses of environmental change over time (Bowker, 2005; Zimmerman \& Nardi, 2010; Baker \& Millerand, 2010; Mauz et al., 2012). Here, we document a front-of-stage 'Big Ecology' research infrastructure, characterised by its orientation to the future. 
We propose to think through the French ecotrons as at once anticipatory and promissory infrastructures. Designed to enhance the epistemic status of ecology as a predictive science, ecotrons promise to secure recognition of the validity and importance of functional ecology from other scientific disciplines engaged in the anticipation of global environmental change (and crucially, from science funders and transnational environmental policy fora). Studies of scientific promise have emphasized the role of promissory rhetoric and scientific visions in attracting investment, audiences, and moral commitments to particular scientific agendas. A predominant focus of this literature has been to technology-driven fields with potential for commercialization, such as biomedicine, nanotechnology and synthetic biology (Brown, 2003; Brown et al., 2003; Frow, 2013). Given what is at stake for 'the emerging bioeconomy' in projections linking ocean acidification and global warming to mass extinctions (Walker, 2016), surprisingly little attention has been paid to the promissory and anticipatory practices of ecologists.

For their proponents, ecotrons promise to federate a multi-national community of ecologists around shared research agendas, agendas which appear closely aligned to policy narratives emerging from recent reconfigurations of the knowledge politics of global environmental change. The influential Millennium Ecosystem Assessment (2005) contributed to a recalibration of ecological research within the policy idiom of "ecosystem services", which anthropocentrically re-defines ecosystem functions as economic services rendered to societies, including food production and water purification (linked to pollination and hydrological cycling), or climate regulation (linked to $\mathrm{CO} 2$ absorption by forests and microorganisms). The discursive success of 'ecosystem services' has met with critical scrutiny. The project to establish private property rights in remnant ecosystems, and financial markets trading in the 'services' they provide has been critiqued as the imposition of a 'neoliberal nature' from the commanding heights of global economic power (eg. Sullivan, 2013). The ways in which ecologists have actively sought to re-present themselves as hard-nosed realists capable of risk-managing capital investments in securitized 'ecological infrastructures' has received less attention.

Early studies of scientific promise emphasized the importance of politico-scientific leaders and their speech acts (van Lente \& Rip, 1998). Akrich (1992) insisted that technical artifacts tell stories, insofar as they are embedded with "scripts", which teach users how to interact with them. Borup et al. (2006) and Millerand et al. (2013) emphasize the role played by material objects and infrastructures in shaping and stabilizing scientists' promises. Philosophers concerned with the cultural dimensions of extinction attribute story-telling capacities to a variety of organisms, arguing that "narrative is a quality of the lives of many (probably most) nonhuman animals" (van Dooren \& Rose, 2012: 4). Research infrastructures encode narratives about the value and relevance of the research they enable. Ecotrons, then, may be important sites for the negotiation of broader civilizational values and narratives of our place in the living world.

Ecotrons are costly research infrastructures, necessarily embedded in claims upon resources, and competition for allies and audiences. The initial decision to fund the construction of the ecotrons was resented by landscape-scale ecologists, whose research on in situ communities involves large trees and animals, which can only be excluded from the controlled interiors of the ecotron. ${ }^{5}$ Our interest here is less in grant politics than in how research priorities "become infrastructures", how once built, they shape future research agendas and policy debates, privileging some research orientations and excluding others (Frickel et al., 2010). We are particularly interested in how the architects and operators of the French ecotrons locate them within a narrative of human vulnerability and resilience to environmental change, establishing professional distance from popular associations of 'ecology' with the defence of biodiversity from destructive economic activity. If there is a tacit social contract emerging, one which re-frames ecologists as expert analysts and managers of the critical ecosystem functions and services needed for 'human well-being', it will be embedded not only in speech acts but in the material configurations of the 'infrastructuring environment'. 


\section{II: A Genealogy of the Ecotron}

The recently built French ecotrons did not emerge from a vacuum. A full genealogy of the ecotron, which we can only indicate here, would trace a number of intersecting histories: of greenhouses constructed for colonial botanical collections, of the aquaria and terraria of in vitro biology, of technologies of climate control and simulation, of the regenerative life-support systems envisioned for long-term space travel and other prostheses. Let us at least suggest that ecotrons hybridize a long lineage of infrastructures that maintain collections of organisms in closed systems, insulated from local conditions and disturbances. We would contend that the lineage of enclosure experiments in constructed, artificial, climate-controlled biospheres is more closely interwoven with the history of ecology than has thus far been recognized.

Ecologists have long aspired to claim the status of a confirmed science of critical relevance to society. Often, they have felt vulnerable to criticisms that ecology was doomed to remain a 'soft science'. The messy contingency, variability, and vast complexity of biotic interactions encountered in the field suggested that ecologists would never be able articulate general 'laws' of ecology through the statistical methods of controlled experimental validation deployed in the laboratory sciences (Martin, 2015). As Schultz (1956) once put it:

\footnotetext{
Plant physiologists who are bequeathed with unlimited funds have elaborated laboratories and greenhouses where nearly every essential feature of the environment can be controlled. Thus, an experiment can be reduced to only one variable such as growth. With complete control over all factors, there should, theoretically, be no unexplained error encountered in the experimentation. [...] Ecologists have two strikes against them - they never are bequeathed with unlimited funds and if they were, they would fall short in controlling most factors of the outdoor environment, as the rainmakers can attest. So their research is redolent with what is called experimental error.
}

Let us then trace our infrastructural genealogy of the ecotron from the 'Phytotron', built in 1949 by the plant physiologist Frits W. Went at Caltech,
Pasadena. Billed as a "fabulous weather factory", the phytotron was designed to study plant growth and acclimatisation, enabling the reproduction of all possible climatic conditions, whether simulating actually existing regional climates from data gathered in other lands, or testing purely experimental, artificial conditions. Light, temperature, humidity, gas content of the air, wind, rain and fog could be held constant or made to oscillate as programmed. Went not only claimed that the scientific questions to be pursued in the phytotron were as complex and important as those pursued by nuclear physicists in cyclotrons, but also that the "methods developed in the phytotron for analyzing the complex interrelations between organisms and their environment" would prove "helpful in an analysis and better understanding of our social and economic system" (Went, 1949: 6).

Whilst not ordinarily included in histories of ecology, the phytotron is emblematic of the mid-20 ${ }^{\text {th }}$ century shift of ecology away from vitalism and the study of biotic communities via organicist metaphors (the "super-organism" of Frederic Clements (1916) for example), towards systems ecology, with its focus on the flows and exchanges of matter and energy between living beings and their abiotic environment, in analogy with a 'cybernetic machine' (Margalef, 1968; Odum, 2000 [1977]). First proposed by the Oxford ecologist Arthur Tansley (1935), the rise of the ecosystem concept and its significance for the constitution of ecology as a discipline has been well-documented by historians (Worster, 1994 [1977]; Golley, 1993; Kingsland, 2005). In a context where ecologists sought to affirm the status of their research, and to transcend a heritage in the field studies of amateur natural history, by the latter $20^{\text {th }}$ century the systems approach had become the cornerstone of ecology's claim not only to scientific authority but also to social and political relevance. Documenting the biogeochemical flows of nutrients and energy through 'systems' abstracted from particular organisms enabled ecologists "to go beyond general conceptions of ecological processes by adding exact measurements, experiments and tests of hypotheses" (Kingsland, 2005: 178). This approach also enabled ecologists to analyse the effects of human activities on ecological processes from the 
local to the global scale. In an exemplary paper, Evelyn Hutchinson (1948) estimated the global carbon budget of the biosphere, offering one of the earliest quantifications of the alteration of the carbon cycle by the industrial combustion of fossil fuels. Analysis was no longer constrained by the need to construct a pure Nature external to social relations. The stage was set for ecology to become the 'subversive science' of modern environmentalism.

Eugene P. Odum's seminal textbook Fundamentals of Ecology played a major role in establishing the functional whole of the ecosystem as the central concept of ecology (Odum, 1971 [1953]). While E.P. Odum can be credited with a major role in the professionalization of ecosystems approach among scientists, it was his brother Howard Tom Odum, with his pioneering big-picture work in whole-system energetics and his idiosyncratic attempts to communicate the importance of this work in his Environment, Power and Society (1971) that brought systems ecology a wide lay audience among those concerned with the global crises of energy and environment (Coleman, 2010: 10-11). Both brothers were influenced by Lotka's effort to mathematize 'physical biology' (Lotka, 1956 [1925]), Lindeman's seminal work on measuring energy flow through the trophic hierarchy (Lindeman, 1942), and their teacher Evelyn Hutchinson's engagement with cybernetics. The difference between them, according to the historian Sharon Kingsland, was that "Eugene thought of the ecosystem in organic terms as though it were an organism in a state of homeostasis, Tom deviated from this organic analogy and increasingly thought of the ecosystem as a machine governed by feedback mechanisms" (Kingsland, 2005: 195).

Systems ecology has been criticized as a machine theory of nature, with a reductionist tendency to focus on quantifiable energy flows. ${ }^{6}$ As Voigt notes,"the main concern is with the material-energetic aspects of interactions; the actual species involved are only of interest insofar as their specific features are relevant to the transformation of matter and energy" (Voigt, 2011: 189). The metaphors, practices and infrastructures of systems ecology as Big Science have been investigated by Kwa (1987; 1993); others have analysed the experimental manipulation of watersheds and the measurement of energy and nutrient flows in the Hubbard Brook Ecosystem study (Hagen, 1992; Bocking, 1997, 2010). Dealing with large, open, unbounded ecosystems, such research programs remained vulnerable to the criticism that in reality, the 'systems' under analysis were far too complex and non-linear to be modelled accurately through the reductionism of the systems approach. We would suggest that nothing exemplifies a cyborg theory of nature better than an infrastructure engineered to put its analytical agenda into effect: what is an ecotron if not the materialization of the ecosystem concept itself? Conceived by functional ecologists to make valid causal claims about ecological processes independent of social values and human presence, there is some irony in that this is to be achieved by constructing an artificially minimalist Nature fully internal to the social relations fixed in the plastic, steel, concrete and data-generating systems of an elaborate technoscience infrastructure.

No genealogy of the ecotron could fail to mention the spectacularly ambitious Biosphere II facility. Built privately by Space Biosphere Ventures between 1987 and 1991 in the Arizona desert, without official research funding or supervision, its designers drew on prior experiments in the Soviet space program such as BIOS-3 (Gitelson et al., 2003: 231-309). BIOS-3 was in turn inspired by the Russian cosmist tradition of ecology initiated by Vladimir Vernadsky's The Biosphere (1926), a work until then relatively unknown in the West. Modelled on Biosphere I (the Earth), an energetically open but materially closed complex ecosystem, Biosphere II was designed as a self-regenerating ecological life support system capable of maintaining an atmosphere and enough food for the eight 'bionauts' who were to be locked inside for two years. Covering more than one hectare with rain forest, coral reef, desert, savannah and farm biomes, it was one of the most airtight structures ever attempted, aiming to leak air at only half the rate of the Space Shuttle. This sealed boundary was its defining structural feature: an attempt to make the 'Earth system' upon which it was built completely exterior to its artificial interior and the select organisms enclosed in this late modern 
Noah's Ark. Biosphere II experienced a number of revealing problems: technical, socio-political, and biological. One was enormous energy consumption, a counter to poorly anticipated 'greenhouse effects'. In order to smooth out volatile extremes of temperature and air pressure which threatened to crack open the dome, or dessicate the plants, huge air-conditioners were retrofitted, which consumed three-times more fossil energy than the solar energy absorbed by the sphere. From an engineering point-of-view, the most difficult problems were related to the capacity of complex eco-systems for unanticipated emergence. ${ }^{7}$ 'Equilibrium' failed to emerge and set in. Carbon dioxide levels rose and oxygen levels fell to debilitating levels, and the stress on the crew resulted in a social polarization into factions who by the end of the enclosure scarcely spoke to one another. Systems ecologists interpreted the successes and failures of Biosphere II as important lessons for planetary civilisation, spurs for the necessary advancement of ecological engineering (Marino \& Odum, 1999).

Biosphere II was refitted in the early 2000s as an experimental platform for research on ecosystem functions under the leadership of Barry Osmond (2005), a colleague of Frits Went and researcher at the Canberra Phytotron. Osmond has since advised researchers in Japan and Sweden on concepts for Biosphere 3 and Boreosphere, a new generation of ecosystem research facilities. By contrast, the Ecotrons appear much more modest in scale and in futurist optimism - although the chief investigator of the Montpellier ecotron mentioned exobiology, the science of life outside Earth, as a potential objective for a "future second generation of ecotrons".

The first research infrastructure to bear the name "Ecotron" was designed in the late 1980s at Imperial College in London under the stewardship of a small group of highly influential ecologists sometimes called the "Silwood mafia", who played an important role in emphasizing the role of mathematically sound statistical analysis of manipulative experiments (Gay, 2013). The first research project undertaken in the London ecotron was a response to the concerns of a 1991 conference on 'Biodiversity and Ecosystem Functions', convened in Bayreuth (Germany) to remedy an almost complete lack of knowledge about the way that biological diversity and its accelerating loss might affect the global Earth-system exchanges of biomass and energy studied in the International Geosphere-Biosphere Programme (19872015). These experiments were foundational to the growing sub-discipline of biodiversity and ecosystem function research (BEF research, or 'functional ecology'), an approach which aims to rigorously apply the physico-chemical functionalism of systems ecology down to the level of the intricate, taxonomically specific phenomena studied by population, community and evolutionary ecologists (Schulze \& Mooney, 1994).

The first research carried out in the London ecotron is known as the biodiversity-functions experiment: it aimed to test the influence of the diversity of species on the functioning of ecosystems (Naeem et al., 1995). Here the aim was to bring new support to the notion that the 'balance of nature' (the sustained equilibrium reached by the successional climax community, to use older terms) is dependent on biodiversity, that the most diverse communities of organisms are also the most stable and productive. John Lawton, a leader of the Silwood Park Ecotron, defended the value of experimental ecology in controlled artificial systems, arguing that "if we cannot understand simplified ecosystems such as those in the Ecotrons, we are unlikely to understand very complex ones" (Lawton, 2001: 178; see also Lawton, 1996; Resetaritts \& Bernardo, 1998). Results were published claiming to prove that less diverse systems were demonstrably less productive and less stable, but the experiments were strongly criticized for experimental biases (Hodgson et al., 1998; Wardle et al., 2000; Naeem, 2000). Detractors argued that the experiment brought no new evidence regarding the effect of species diversity: they argued that the experimental results rather reflected a change in the functional diversity of plants (i.e. the selection of species more or less productive of biomass) rather than the change in the taxonomic diversity of species. After this controversy, experiments in the ecotron focused increasingly on the functional side of the biodiversity-ecosystem functions problematic. Moving from biodiversity (as species richness) to functional diversity, ecologists 
increasingly focused on "functional traits", that is, the measurable characteristics of organisms that directly contribute to ecosystem functions (for example, capacity for nitrogen or carbon fixation, water uptake, nutrient requirements, resistance to chemical pollution, seed dispersal, trophic efficiency and light requirements, leaf morphology, growth rate, reproductive rate, and so on). ${ }^{8}$

The French Ecotrons descend directly from the Phytotron at Caltech, via the person of Frode Eckardt, the Montpellier eco-physiologist who worked in Went's laboratory in the late 1950s. As a principal investigator at the Centre d'Etudes Phytosociologiques et Ecologiques (CEPE, established in 1961), in 1963 Eckardt submitted the first proposal for an ecotron to Montpellier University, to study the ecophysiology of plants and ecosystem/atmosphere gas exchange (and not plant development, as in most phytotrons at that time). The proposal was rejected, perhaps influenced by the fact that CEPE was home to the Zurich-Montpellier school of communitarian vegetation studies, which took Braun-Blanquet's Plant Sociology (1932 [1928]) and its floristic classification of plant associations as the paradigmatic text. Many community ecologists were sceptical of the equilibrium systems ecology of the Odum brothers (Nicholson, 2013), and the French tradition of ecology, rooted in regional schools of botanical geography (Matagne, 2011), shared little common intellectual history with the Cold War meta-science of cybernetics then ascendant in the United States. Nevertheless, Eckardt went on to become an international figure, working with physicists, engineers and atmospheric chemists to pioneer the development of climatecontrolled chambers and micro-meteorological techniques for ecophysiology, developing techniques for extrapolating local-scale quantifications of 'biomass productivity' (e.g. the efficiency of photosynthesis in converting solar energy, water and carbon-dioxide into biomass) up to the level of the 'terrestrial productivity' studied by his fellow researchers in the International Biosphere Program of the 1960s (Eckardt, 1968; Saugier et al., 2001). In 1988, the research focus of CEPE was reoriented toward international trends, as reflected in the change of name to the Centre d'Ecologie Fonctionnelle et Evolutive (CEFE).
The execution of the current Ecotron was carried forward by Jacques Roy, who studied under Eckardt.

Today, large controlled chambers for the measurement of gas exchanges between plants and the environment exist in most major universities and agronomic institutes: for example New Zealand's Biotron, the Bioklima project in Norway, the ecotron projects in Germany and in Belgium. Many more ecotron-like facilities are in progress. ${ }^{9}$ Phytotrons, designed for plant physiology, differ from ecotrons in that the latter are interested in theorising inter-species interaction, and may thus include insects and small animals, although increasingly ecotron experiments focus on microbial communities. While all the ecotron-like facilities are designed to condition and measure gas exchanges between plants and the environment in experimental enclosures, the latest facilities offer more sophisticated technologies of environmental control, enabling the precise programming of $\mathrm{CO} 2$ concentrations in water and air, precise measurements of evapotranspiration in plants, and the tracing of biophysical exchanges between plants and soil microbiota through proteomic technologies.

Funding for the French ecotrons was awarded by the National Center for Scientific Research (CNRS) immediately prior to the establishment of a CNRS division dedicated exclusively to ecology and environmental science. Until then, ecology had been part of bigger departments devoted to the life sciences. The inauguration of the ecotrons was contemporaneous with the re-foundation of the French Society for Ecology, and with Ecology 2010, a major international conference hosted in Montpellier by ecotron director Jacques Roy. On their websites, the ecotrons are presented as cutting-edge research facilities for systems ecology, boasting a suite of technical advantages in order to attract top-ranked French and international research teams. ${ }^{10}$ The ecotrons thus materialize a relative re-balancing of resources and funds in favour of ecology within French science policy, by institutions that have long been reluctant to recognize a discipline tainted by association with environmental activism and suspected of limited potential for scientific prestige. 


\section{III: An Infrastructure of Promise}

The genealogy of the ecotron we have thus far sketched can be read both as an outline for critical research in (bio)infrastructure studies, and as an interpretive historical framework giving context to the recent ascendance of functional ecology. With both theoretical agendas in mind, we now discuss in more detail the material patterns of the French ecotrons and the research agenda they encapsulate. Three major narrative themes emerged from our fieldwork, suggesting how the recently built French ecotrons encrypt a particular promise of relevance, authority and importance for ecology.

\section{1- Ecology as a "Hard" Science}

The Foljuif and Montpellier ecotrons cover several hectares at their respective locations in Northern and Mediterranean France. Their major architectural feature is the hierarchical division of the buildings into two interlocking but separate interiors: the first being the precisely engineered boundary or 'membrane' containing and enclosing the series of 'ecosystems', with their atmospheres, water circulation systems, plants, soils and micro-fauna (the Foljuif ecotron specializes in the simulation of aquatic biomes); and the second, the maintenance rooms and laboratories, where scientists and engineers maintain the circulatory systems which condition environmental parameters and the information systems which sense and record ecosystem processes, functions and adaptive responses to these settings. The maintenance and measurement rooms are generally located below or behind the 'ecosystem'. Experimental units are distinguished into three classes by the size of the chambers: microcosms, mesocosms and macrocosms. We focus here on those designated as 'macrocosms', noting that this term is applied with somewhat less grandeur than in the Biosphere 2 facility (in terms of both species diversity and the intention to function as a long term sealed life support system for a human community). The macrocosms of the French Ecotrons are enclosed in hemispheric domes of transparent plastic film with a 2 metre radius, atop cylindrical containers allowing a soil depth of up to $2 \mathrm{~m}$. They can contain up to 8 tons of 'ecosystem' (see Fig 1 and 2).

As was explained to us by an ecologist who has followed the ecotrons since their construction phase as a PhD student at Montpellier, the critical material characteristic of the ecotron, and its advantage to ecological research, is "that you can consider your system as a closed system: you can measure what goes in and out". The reference to physics as the experimental gold standard for ecology has been inherent in the term 'ecosystem'

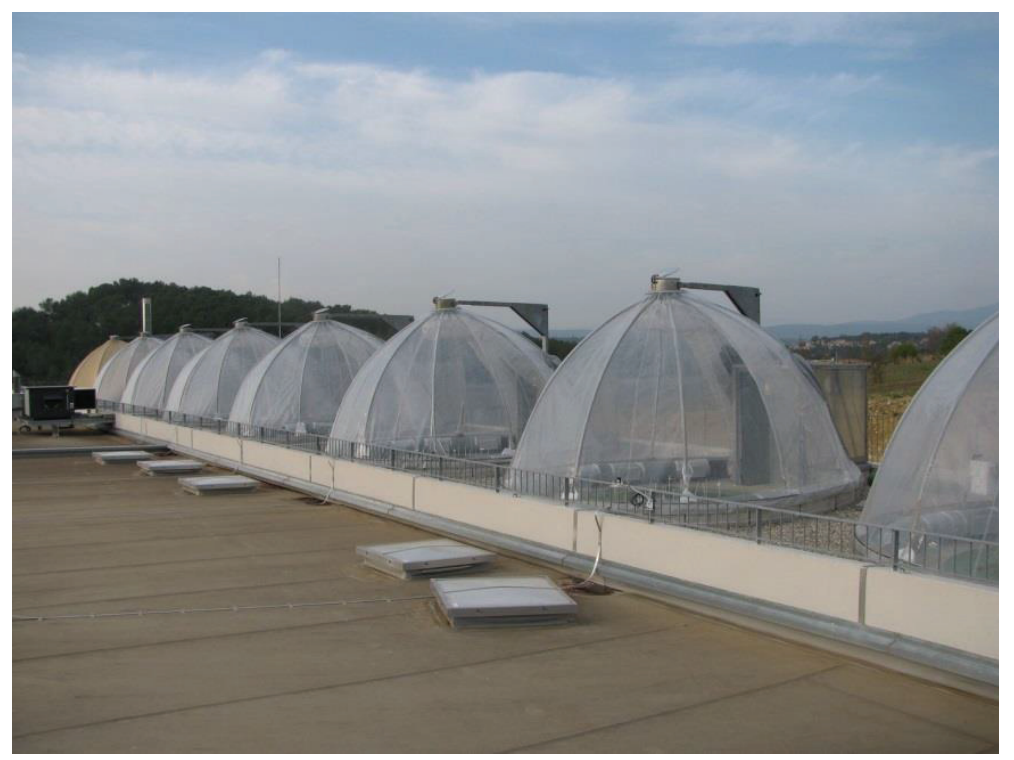

Figure 1. The ecotron in Montpellier showing part of the series of mesocosm domes. Source: www.ecotron.cnrs. fr (accessed: 23.8.2016) 


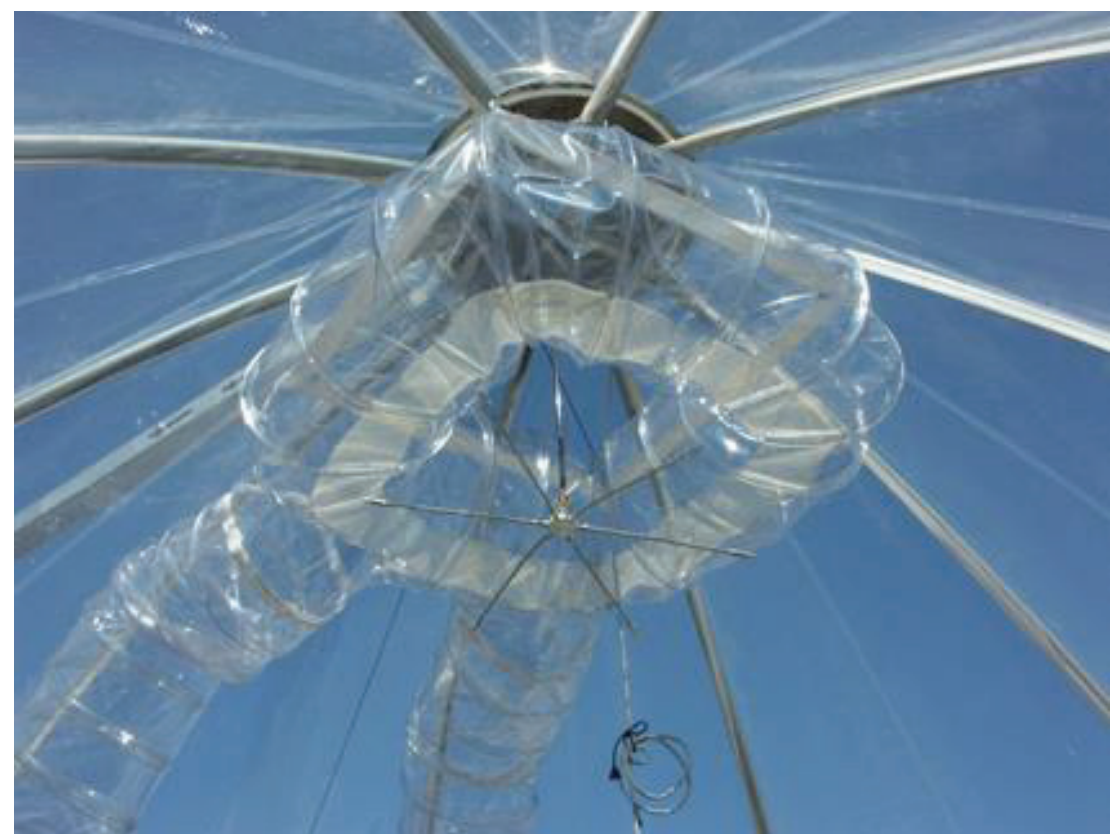

Figure 2. Interior of an ecotron mesocosm chamber showing equipment for controlling the circulation of atmospheric gases and humidity. Source: www.ecotron.cnrs.fr (accessed: 23.8.2016)

since it was first proposed by Tansley. Whereas the 'ecosystem' has tended to function as an analytical construct for ecologists faced with the incredible complexity of open ecological communities never completely separable from the whole Earth's biosphere, the ecotron promises the technical materialization of a bounded 'system' which is 'closed' in the sense of thermodynamics (e.g. energetically open to solar radiation and heat transfer, closed to material inputs and outputs). This promises the possibility of measuring elemental fluxes between the living and non-living parts of the ecosystem, as well as inter-species interactions, without external disturbance. Experiments in the ecotrons are hermetically isolated by the plastic dome from 'contamination' by the outside atmosphere and animals, avoiding the possibility that (say) birds and insects might introducing nitrogen via faeces - an issue encountered in the case of outdoor experimental devices such as flux towers which also aim to alter and measure greenhouse gas exchanges between plants and the air."11

Experimental control clearly contributes to ecologists' hope to move ecology up the hierarchy of disciplines, by 'grounding' it in chemistry, physics and finally mathematical equations. A young professor of ecology specializing in interactions between plants, insects and soils explained her enthusiasm for the Foljuif facility in these terms:

\footnotetext{
“Ecotrons are about really achieving a highly refined approach by manipulating very precisely each ecosystem parameter, especially each parameter of the biodiversity, each parameter of the interaction networks, in order to look at what happens - other things being equal. Such experimental conditions are really close to what we have in big infrastructures in physics or in chemistry: it is hard science with a capital H."
}

Ecotrons' isolation from outside weather is a precondition of their ability to make their own weather: they can modulate (or simulate) sunlight intensity and periodicity, automate artificial 'seasons', they can pre-program patterns of temperature, wind, humidity, precipitation, soil moisture and concentrations of $\mathrm{CO} 2$ and methane. Experiments can be run for up to three years. Software which sets the parameters and allows the automation of experimental design also automatically quality checks and manages the data logged several times per hour by instruments such as quantum sensors and spectrometers for measuring light, and anemometers for sensing wind. Other instruments measure leaf gas exchange and chlo- 
rophyll fluorescence, stomatal conductance, and fluxes of methane and carbon-dioxide between soil, atmosphere and canopy.

An ecologist studying plant physiology in Montpellier expected that the ecotrons would make it possible to achieve detailed and robust knowledge of the ecological processes likely to back up in situ observations: "[my research includes] a long-term and in situ part, and then a part of experimental control in the ecotron in order to understand which processes are at stake".

Ecotrons do not necessarily convert ecology into an in vitro lab-science: instead they offer to buttress in natura ecosystem research through isolating and testing potentially fundamental ecological interaction mechanisms ceteris paribus through multi-factorial analysis. The identical series of experimental units in the ecotrons incorporates the statistical standards of the highestranked ecological journals, making it possible to run at least 12 replications of the same manipulation simultaneously. The importance of statistical replication for scientific recognition of results is emphasized in the ecotrons' institutional websites: there are 12 macrocosms in Montpellier and 18 units in Foljuif (with a further 24 mesocosms approaching completion in Montpellier at the time of writing).

\section{2 - Ecology as an Anticipatory Science of Crisis Adaptation}

If ecologists' aspirations to ground their science in the methods and revealed laws of physics are not new, the French ecotron infrastructure suggests the reconfiguration of ecology into an anticipatory policy science, linked to climate science and its scenario modelling. Whilst not predictive in the strict sense, ecotrons make possible the enactment of currently non-existing climates, those of past geological eras when particular species appeared, or most often, the anthropogenic climates of the future. The last experiment carried out in the Silwood Park ecotron, entitled "Sealing Carbon and Life in Ecotrons" pointed to the future of ecotron research. For the chief scientist of the Montpellier ecotron, the infrastructure's significant design feature is "the possibility of simulating the environmental conditions of the future" and addressing "new questions of prediction of ecosys- tem and biodiversity functioning" in the context of climate change. There is a shared conviction amongst the ecologists we interviewed that "biodiversity's future is climate change" (to quote the director of the French Foundation for Research on Biodiversity).

Clearly articulated on the website of the Montpellier ecotron is its mission of "preserving and improving ecosystem services and securing food supply". Running simulations of the scenario projections of the Intergovernmental Panel on Climate Change (IPCC), the first experiment carried out in Montpellier studied the impact of heatwaves and drought on grasslands, represented by turf samples that had been extracted from pastures in central France, previously treated and monitored in situ. A key-objective of this experiment was to anticipate and prepare for changes in grazing and farming practices. Several experiments conducted since have been directed to the physiological response of wine grape varieties to elevated temperatures and extreme events. Experimental simulations of climate scenarios suggest the possibility of forecasting the parameters of ecosystem's functional resilience, helping societies - or at least the valuable agricultural sectors of privileged societies - to preemptively adapt to global change.

Plant physiology and growth are at the core of a number of experimental scenarios brought to life in the ecotrons. Several ecotron experiments aimed to study how climate scenarios might impact plants' physiological mechanisms such as photosynthesis, evapotranspiration and growth. These functional traits are analysed down to "the level of the leaf", to quote a summary of an on-going Montpellier experiment. Of course ecologists are fully aware that ecosystem functions depend on more complex assemblages of species, and there are also experiments endeavouring to understand how climate change may impact communities including snails and insects. Yet, by design, the size of ecotrons excludes the study of complex communities composed of large plants and animals, not to mention humans. Rather, the focus on the adaptive capacity of plant physiology anticipates a generalised vulnerability, seeking to understand the capacity for resilience of ecosystem functions in the extreme environ- 
ments transposed from the future of the climate scenario into the experimental present. This focus on 'reliability engineering' is predicated on a systemic indifference to questions of biodiversity conservation. According to one interviewee, a community ecologist skeptical of the grandiose project of the Montpellier ecotron, "it was strongly pushed forward by some people in the lab who were ecophysiologists", to the exclusion of other priorities that may be deemed ethically important: "obviously ecotrons were made not to work on extinction, but on ecosystems".

Experimental scenarios in the ecotrons reflect the narrative that "services provided by ecosystems are under threat." ${ }^{12}$ Ecology's promissory contract now involves anticipating the effects of global change on critical ecosystem functions and services. The concern of the original Silwood Park experiments, to test intuitive propositions that biodiversity preservation was necessary to maintain ecological stability and abundance, has faded away. The minimalist ecosystems assembled inside the ecotrons are enlisted in the project of identifying the minimal biosphere necessary to retain the agro-infrastructures that secure "human well-being".13 As such, contemporary ecotron research side-steps deeply political questions about the possibility of prevention in favour of the necessity of adaptation. Ecologists thus risk naturalising as inevitable a choice, amongst many future worlds arguably yet still possible, of one in which multispecies abundance has been deemed safely surplus to the operational requirements of critical infrastructure systems, be they biological or industrial. ${ }^{14}$

\section{3 - Ecology as (Micro)Ecological Engineering Science}

The experimental architecture of the ecotron enables the exploration of the properties of microbial communities, such as soil microbes which interact with plant roots, or water-dwelling phytoplankton. Most microorganisms cannot be studied in laboratory conditions, usually their identification must be carried out outdoors. Ecotrons are large enough that researchers can examine specific quantities of soil or water and identify the functional and evolutionary capacities of microbial communities using proteomic technologies. ${ }^{15}$
The incorporation of sophisticated lysimeters in the ecotron monitoring room enhances understanding of the properties and potentialities of soil biodiversity. Lysimeters are devices which measure the transport of water between organisms and their environment; such as the interaction between transpiration (water flows through living plants), and the evaporation of water from soil and water bodies. As one eco-physiologist explained to us: "the subterranean part of ecosystems, in the Montpellier ecotron at least, was specifically designed, [..] to make it possible to work on the subterranean part". Unlike Biosphere II and the Silwood Park ecotron, both criticized for not paying enough attention to soil microbiology, the French ecotrons aim to open "the extraordinary black box" (in the words of the same informant) of microbial diversity in soils.

The lead researcher of a soil ecology laboratory explained that the ecotron was the ideal platform for developing applied micro-ecological engineering. For him, ecology should be about "manipulating and tinkering with organisms in order to obtain a certain effect", for instance (to give proffered examples) designing green areas with enhanced capacities to absorb gases, or modifying the properties of the soil under urban roads so as to increase the absorption of $\mathrm{CO} 2$ released by cars. For this scientist, the ecotron offered opportunities for ecologists to lose their 'subversive' counter-cultural image, and through mastery of the biogeochemical potentials of microbial life, to achieve a scientific prestige and industrial utility equivalent to molecular biology:

\footnotetext{
"Ecological engineering is a great opportunity for ecology, as medicine is for physiology or energy for physics: [ecologists have shifted] from birds to corridors and now the role of living beings in heat exchanges: it is not hippie-like engineering, it is about biotechnology".
}

Ecotrons also offer advantages to ecotoxicologists. Chemically polluted ecosystems are next to impossible to analyse in situ. Due to the large number of synthetic chemical species diffused throughout the environment, which may be latent or bioactive well below detection limits, alone or in combination with other residues, it is very difficult to isolate causal pathways of toxicity through 
biotic communities. The costs of combinatory toxicology studies are prohibitive, accurate long term monitoring and ecological data sets are rare, and in situ experiments would require polluting relatively pristine sites. Ecotrons make it possible to reduce the daunting complexity faced by ecotoxicologists, the better to understand how particular microorganisms might decrease pollutant levels or neutralise their impacts (bio-remediation). The use of advanced proteomics and lysimeters promises to profoundly increase knowledge of the microbial foundations of the biosphere, knowledge that may be applied to optimise ecosystem functions and 'services', thereby reconfiguring ecology from a science of moral prophecy to one of pragmatic, piecemeal engineering.

There is an important affective dimension associated with the prospect of exploring the little-known microcosmos inside the ecotrons, an optimism far removed from the disheartening scenarios of depletion, endangerment and extinction that characterise the visible macrocosm of plants and animals studied by field ecologists. As one microbial ecologist explained,

"You can speak of extinction when you speak of iconic species, but for microbiology it's not the case at all: we are at the beginning of an exploration step and not really of an extinction step; there is an explosion of possibilities, not the contrary".
Another interviewee spoke of the "Terra Incognita of biodiversity (....) on which the whole of life on Earth depends". Lost is the earlier vocation of the Silwood ecotron in demonstrating biodiversity loss and habitat destruction as a threat to life as a whole, found is the "outstanding diversity" of potentials disclosed by microorganisms' metabolic role in global biogeochemical cycling and in the evolutionary history and trajectory of the biosphere. The fact that microorganisms play a major role in the Earth system is critical to ecotrons' claim to analyse anthropogenic changes to planetary processes unfolding in geological time on the basis of miniature experimental ecosystems comprising only a couple of pot plants in an intensively instrumented bubble (see Fig 3). Such are the problems of extrapolation facing in vitro ecologists, who to borrow a line from Peterson \& Hastings (2001), are in the business of 'designing mousetraps to catch elephants.'

\section{Conclusion}

Our inquiry sits well with Calvert's (2013) suggestion that the discipline-building style of $20^{\text {th }}$ century "big science" is receding. In its place we see an integrative science that blurs the boundary between experimental research and geoengineering interventions, and up-scales both in the hope to meet the "grand challenges" of global

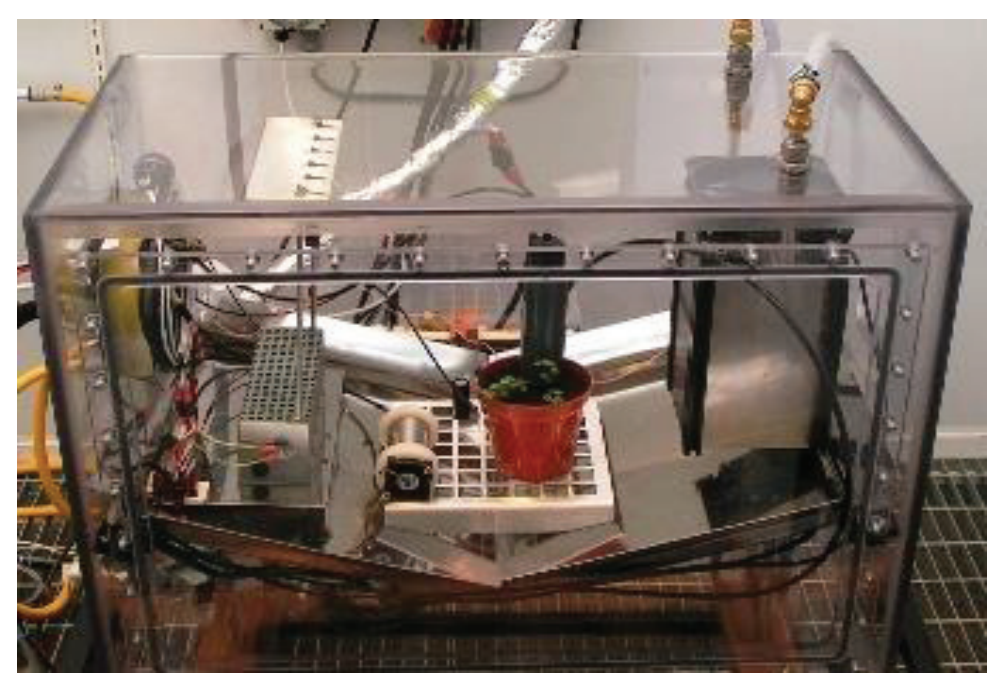

Figure 3. Ecotron experiment on the functional responses 'down to the level of the leaf' of plants and soil microbes to climate change simulations. Source: http://www3.imperial.ac.uk/cpb/history/theecotron/research/ scaleproject (accessed: 25.8.2016) 
warming, habitat fragmentation, even the global loss of whole biomes such as coral reefs.

At the turn of the millennium, Slobodkin (2000) suggested a new role and social vocation for ecology. Rather than assuming professional responsibility for the agonistic task of "stemming the tide of environmental degradation," as claimed by Bazzaz et al. (1998), Slobodkin argued that ecologists could more realistically aspire to the less politically charged, more pragmatic role of enabling the "duplication" of ecological services. The French ecotrons bring into being a world for ecologists to act within, a world in which they will help adapt critical ecosystem functions in and through dramatic global change, rather than demonstrate the necessity of halting the destructive economic practices that drive biodiversity loss.

This shift in ecology's self-conceived task, from protective conservation to pre-emptive security is certainly not specific to France: it is currently disputed in international ecological journals (Doak et al., 2014). It is possible that the move to re-articulate ecology's relevance in terms of vital systems security might be especially significant in France, given that many of the French researchers we interviewed distanced themselves from environmentalism, an ideology seen as opposed to "neutral" science. The political shift from a'subversive' to a 'subordinate' role for ecology is apparent in the comments of a senior ecologist at the Foundation for Biodiversity Research, who expressed the need for ecologists to take their distance from "fauna and flora" concerns in order to retain access to decision-makers, funders and stakeholders: "It is not in saying "we need to protect beasties" that we can really manage [to be listened to]".

Ecologists and environmental science professionals today work in an international policy environment defined by official commitments to market-based 'solutions' such as carbon trading and 'biodiversity offsetting' schemes. It seems to us, as Bonneuil (2015) has suggested, that most are unaware of the extent to which this ideological context reflects the historical success of US corporations in organising globally to roll-back the science-based environmental regulations and institutions of the 1970s. This continuing project has been carried through a network of neoliberal think-tanks including the Heritage Institute, established in 1973 by ultra-conservative millionaires and US business interests with the selfavowed intention to "strangle the environmental movement" (Heritage Institute, 1990, in Bonneuil, 2015: 486).

Energetically open to solar insolation and heat-transfer but closed to material inputs and outflows, ecotrons materialize and offer proof of the 'ecosystem' concept itself. Immunised from the turbulent complexity of the planetary-scale ecosystem outside the system boundary, ecotron chambers contain carefully selected biotic communities of minimal complexity, such that the fundamental 'nature' of ecological processes can be analysed with physico-chemical precision. This attempt to engineer a 'pure' nature, from which to construct a 'hard' science, from which to develop precise techniques of control-engineering, carries all the hallmark ambiguities, ironies and figureground reversals of the cyborg sciences (e.g. Haraway, 1991; Mirowski, 2002).

Model worlds, the highly ordered microcosmic interiors of the ecotrons are dependent upon connection to the networks of urban, industrial infrastructures that secure the 'good life' of post-industrial knowledge economies - roads, electricity grids, water utilities, the internet. Ecotrons rigorously exclude not only 'non-target' organisms, but what Aradau (2010: 508) labels the 'underbelly' of urban infrastructure - the accumulated wastes, dirty water and pollution expelled from the 'end of the pipe'. Yet the raison d'être of the ecotron is to explore the 'endogenous crisis' of global economic infrastructure: the catastrophic possibilities of (eco)system failure caused by these flows. The contemporary side-lining of biodiversity concerns in the ecosystem functions research suggests something of an 'infrastructural inversion': the minimal biosphere enclosed inside the ecotron reveals the open biosphere outside as a life support system, one that might be engineered to maintain a minimum level of essential functions and 'services', even through unprecedented climate change and extinction events. Perhaps there is a wider lesson in Spring's (1985) observation that, "the simpler the biological components of the system become, the more externalised and complete the control must be" (cited in Beyers \& Odum, 2012 [1993]: 25). 
Ecotrons encode narratives of what ecology is and will become, what it is for, and what it is no longer. Not only do they conduct and channel research agendas that have been accorded epistemic authority, they also, intentionally or otherwise, encapsulate tacit ontological commitments to biopolitical questions of value and security, being and time, relation and classification, order and chaos, obligation and abandonment.

\section{Acknowledgements}

Celine Granjou wishes to acknowledge research support from the Agence Nationale de la Recherche, PANBioptique project (ANR 09-SSOC053-01) and to the scientists who accepted to share their experience and views regarding the research carried out in the ecotrons. Jeremy Walker is grateful to Virginie Maris and her colleagues at the Centre d'Ecologie Fonctionnelle et Evolutive (CNRS, Montpellier) and to Christophe Bonneuil of Centre Alexandre-Koyré (CNRS, Paris) for supporting research visits that provided inspiration for this article. The authors would like to thank two anonymous reviewers for helpful comments on earlier drafts of the article. 


\section{References}

Akrich M (1992) The De-Scription of Technical Objects. In: Bijker W \& Law J (eds) Shaping Technology/Building Society: Studies in Sociotechnical Change. New York: MIT Press, 205-224.

Allee WC, Park O, Emerson AE, Park T \& Schmidt KP (1949) Principles of Animal Ecology. St Louis MO (USA): WB Saunders Co.

Aradau C (2010) Security that Matters: Critical Infrastructure and Objects of Protection. Security Dialogue 41(5): 491-514.

Baker S \& Millerand F (2010) Infrastructuring Ecology: Challenges in Achieving Data Sharing. In: Parker J, Vermeulen N \& Penders B (eds) Collaboration in the New Life Sciences. London: Ashgate, 111-138.

Bazzaz F, Ceballos G, Davis M, Dirzo R, Ehrlich PR, Eisner T, Levin S, Lawton JH, Lubchenko J, Matson PA, Mooney H, Roughgarden JE, Saruhkan J, Tilman DG, Wall D, Vitousek P, Walker B, Wilson EO \& Woodwell GM (1998) Ecological Science and the Human Predicament. Science 282: 879.

Beyers RJ \& Odum HT (2012 [1993]) Ecological Microcosms. Dordrecht: Springer Science \& Business Media.

Bocking S (1997) Ecologists and Environmental Politics: a History of Contemporary Ecology. Yale: Yale University Press.

Bocking S (2010) Organizing the Field: Collaboration in the History of Ecology and Environmental Science. In: Parker J, Vermeulen N \& Penders B (eds) Collaboration in the New Life Sciences. London: Ashgate, 15-36.

Bonneuil C (2015) Tell me Where You Come From, I Will Tell You Who You Are: A Genealogy of Biodiversity Offsetting Mechanisms in Historical Context. Biological Conservation 192: 485-491.

Borup M, Brown N, Konrad K \& van Lente H (2006) The Sociology of Expectations in Science and Technology. Technology Analysis \& Strategic Management 18(3-4): 285-298.

Bowker GC (2005) Memory Practices in the Sciences. Cambridge: the MIT Press.

Bowker GC \& Star SL (1999) Sorting Things Out: Classification and its Consequences. Cambridge: MIT Press.

Braun-Blanquet J (1932 [1928]) Plant Sociology: The Study of Plant Communities.

New York: McGraw-Hill.

Brown N (2003) Hope against Hype: Accountability in Biopasts, Presents and Futures. Science Studies 16(2): 3-21.

Brown N, Rip A \& Van Lente H (2003) Expectations in \& about Science and Technology, Expectations workshop (University of Twente) 12-14, June 2003.

Calvert J (2013) Systems Biology, Big Science and Grand Challenges. BioSocieties 8(4): 466-479.

Clements F (1916) Plant Succession: an Analysis of the Development of Vegetation. Washington: Carnegie Institute.

Coleman DC (2010) Big Ecology: the Emergence of Ecosystem Science. Berkeley: University of California Press.

Doak DF, Bakker F, Goldstein VJ \& Hale BE (2014) What is the Future of Conservation? Trends in Ecology and Evolution 29(7): 77-81.

Eckardt FE (1968) Functioning of Terrestrial Ecosystems at the Primary Production Level. Paris: UNESCO.

Edwards PN (2010) A Vast Machine. Computer Models, Climate Data, and the Politics of Global Warming. Cambridge: MIT Press.

Frickel S, Gibbon S, Howard J, Kempner J, Ottinger G \& Hess D (2010) Undone Science: Charting Social Movement and Civil Society Challenges to Research Agenda Setting. Science, Technology \& Human Values 35 (4): 444-473. 
Frow EK (2013) Making Big Promises Come True? Articulating and Realizing Value in Synthetic Biology. BioSocieties 8: 432-448.

Gay H (2013) The Silwood Circle: a History of Ecology and the Making of Scientific Careers in Late TwentiethCentury Britain. London: Imperial College Press.

Gitelson II, Lisovsky GM \& Macelroy RD (2003) Manmade Closed Ecological Systems. London: Taylor \& Francis.

Golley FB (1993) A History of the Ecosystem Concept in Ecology: More than the Sum of the Parts. Yale: Yale University Press.

Granjou C \& Arpin I (2015) Epistemic Commitments: Making Relevant science in Biodiversity Studies. Science Technology and Human Values, forthcoming.

Hagen J (1992) An Entangled Bank: the Origins of Ecosystem Ecology. New Brunswick: Rutgers University Press. Haraway D (1991) Simians, Cyborgs and Women: The Reinvention of Nature. New York; Routledge.

Hodgson K, Thompson P, Wilson J \& Bogaard A (1998) Does Biodiversity Determine Ecosystem Function? The Ecotron Experiment Reconsidered. Functional Ecology 12(5): 843-848.

Hutchinson GE (1948) Circular Causal Systems in Ecology. Annals of the New York Academy of Sciences 50: 221-246.

Kingsland S (2005) The Evolution of American Ecology: 1890-2000. Baltimore: John Hopkins University Press.

Kwa C (1993) Modelling the Grasslands. Historical Studies in the Physical and Biological Sciences 24 (1): 125-155.

Kwa C (1987) Representations of Nature mediating between Ecology and Science Policy. The Case of the International Biological Program. Social Studies of Science 17 (3): 413-442.

Lawton JH (2001) Ecological Experiments with Model Systems. In: Resetarits WJ \& Bernardo J (eds) Experimental Ecology: Issues and Perspectives. Oxford: Oxford University Press, 170-181.

Lawton JH (1996) The Ecotron Facility at Silwood Park: The Value of "Big Bottle" Experiments. Ecology 77: 665-669.

Lindeman R (1942) The Trophic-dynamic Aspects of Ecology. Ecology 23(4): 399-417.

Lotka A (1956 [1925]) Elements of Mathematical Biology. New York: Dover.

Marino B \& Odum HT (1999) Biosphere 2: Introduction and Research Progress. Ecological Engineering 13 (1-4): 3-14.

Martin LJ (2015) Mathematizing Nature's Messiness: Graphical Representations of

Variation in Ecology, 1930- present. Environmental Humanities 7: 59-88.

Matagne P (2011) The French Tradition in Ecology: 1820-1950. In: Schwarz A \& Jax K (eds) Ecology Revisited. Reflecting on Concepts, Advancing Science. New York: Springer, 287-306.

Mauz I, Peltola T, Granjou C, Van Bommel S \& Bujis A (2012) How Scientific Visions Matter: Insights from Three Long-Term Socio-Ecological Research (LTSER) Platforms under Construction in Europe. Environmental Science and Policy 19 (20): 90-99.

Margalef R (1968) Perspectives on Ecological Theory. Chicago: University of Chicago Press.

Millennium Ecosystem Assessment (2005) Ecosystem and Human Well-being. Synthesis Reports: Island Press.

Mirowski P (2002) Machine Dreams: Economics Becomes a Cyborg Science. Cambridge: Cambridge University Press.

Millerand F, Ribes D, Baker KS \& Bowker G (2013) Making an Issue out of a Standard: Storytelling Practices in a Scientific Community. Science, Technology and Human Values (38)1: 7-43. 
Naeem S, Thomson LJ, Lawler SP, Lawton JH \& Woodfin RM (1995) Empirical Evidence that Declining Species Diversity May Alter the Performance of Terrestrial Ecosystems. Philosophical Transactions: Biological Sciences 34(1321): 249-262.

Naaem S (2000) Reply to Wardle et al. Bulletin of the Ecological Society of America 81(3): 241-246.

Nicholson M (2013) Community Concepts in Plant Ecology: from Humboldtian Plant Geography to the Superorganism and Beyond. Web Ecology (13): 95-102.

Odum EP (2000 [1977]) The Emergence of Ecology as a New Integrative Discipline. In: Keller DR \& Golley FB (eds) The Philosophy of Ecology: From Science to Synthesis. Athens \& London: University of Georgia Press, 194-203.

Odum EP (1971 [1953]) Fundamentals of Ecology. Philadelphia: W.B. Saunders.

Odum HT (1971) Environment, Power and Society. New York \& Sydney: Wiley Interscience.

Osmond B (2005) Experimental Ecosystem and Climate Change Research in Controlled Environments: Lessons from the Biosphere 2 Laboratory 1996-2003. In: Omasa K, Nouchi I \& de Kok JL (eds) Plant Responses to Air Pollution and Global Change. Tokyo: Springer, 173-184.

Resetarits WJ \& Bernardo J (eds) (1998) Experimental Ecology: Issues and Perspectives. Oxford: Oxford University Press.

Saugier B, Roy J, \& Mooney HA (2001) Terrestrial Global Productivity: a Volume in Physiological Ecology. San Diego: Academic Press.

Schulze ED \& Mooney HA (eds) (1994) Biodiversity and Ecosystem Function. New York: Springer.

Schultz A (1956) The Use of Regression in Range Research. Journal of Range Management (9): 41-46.

Slobodkin LB (2000) Proclaiming a New Ecological Sub-discipline. Bulletin of the Ecological Society of America 81(3): 223-226.

Slotjerdijk P (2011) Bubbles: Spheres, Volume I: Microspherology. South Pasadena: Semiotext(e).

Star SL \& Griesemer JR (1989) Institutional Ecology, Translations and Boundary-objects: Amateurs and Professionals in Berkeley's Museum of Vertebrate Zoology. Social Studies of Science 19(3): 387-420.

Star SL \& Ruhleder K (1996) Steps Toward an Ecology of Infrastructure: Design and Access for Large Information Spaces. Information System Research 7(1): 111-134.

Sullivan S (2013) Banking Nature? The Spectacular Financialisation of Environmental Conservation. Antipode 45(1): 198-217.

Takacs D (1996) The Idea of Biodiversity. Philosophies of Paradise. Baltimore: Johns Hopkins University Press.

Tansley A (1935) The Use and Abuse of Vegetational Concepts and Terms. Ecology (16): 285 -307.

Van Dooren T \& Rose DB (2012) Storied Places in a Multi-species City. Humanimalia 3(2): 1-27.

Van Lente H \& Rip A (1998) The Rise of Membrane Technology: From Rhetorics to Social Reality. Social Studies of Science 28(2): 221-254.

Vermeulen N (2009) Supersizing science: On building large-scale research projects in biology. PhD thesis: Maastricht University.

Vernadsky V (1926) The Biosphere. Leningrad: Nauch.

Voigt A (2011) The Rise of Systems Theory in Ecology. In: Schwarz A \& Jax K (eds) Ecology Revisited: Reflecting on Concepts, Advancing Science. New York: Springer, 183-194.

Walker J (2016) The Creation to Come: Pre-empting the Evolution of the Bioeconomy. In: Connor L \& Marshall J (eds) Environmental Change and the World's Futures: Ecologies, Ontologies, Mythologies. Sydney: Routledge, 264-281. 
Went FW (1949) The Phytotron. Engineering and Science, 12(9): 3-6.

Wardle DA, Huston MA, Grime JP, Berendse F, Garnier E, Lauenroth WK, Setälä H, \& Wilson SD (2000) Biodiversity and Ecosystem Function: an Issue in Ecology. Bulletin of the Ecological Society of America 81 (3): 235-239.

Worster D (1994 [1977]) Nature's Economy: A History of Ecological Ideas. Cambridge: Cambridge University Press.

Zimmerman A \& Nardi BA (2010) Two Approaches to Big Science: An Analysis of LTER and NEON. In: Parker N, Vermeulen N \& Penders B (eds) Collaboration in the New Life Sciences. London: Ashgate, 65-84.

\section{Notes}

1 In his monumental 'Spheres' project, the continental philosopher Peter Sloterdijk (cited above, 2011: 28) has initiated a compelling mode of metaphysical inquiry which he dubs 'sphereology'. Slotjerdijk characterises the the modern individualism of the Cartesian cogito, which thinks itself into relation with the world, as 'placental nihilism'. An ontology of a priori disconnection and foundational aloneness, it denies in the first place the vital, material unity of the womb-bound child with the body and being of the 'expecting' mother, and by extension, all of that out of which we are born. His 'spheres' are 'psychoimmunological spheres of protection': whilst an adequate critique of Slotjerdijk is beyond the scope of this article, a critical appropriation of sphereology for a sociology of the 'biosphere' and its technosciences seems a fruitful prospect. An urgent research agenda here would be the under-appreciated history by which systems ecology has come, through the discourse of 'ecosystem services', to be politically subordinate to the 'biospheric nihilism' of its sister science of economics, as the latter has becoming increasingly indistinguishable from neoliberal political philosophies and governmental techniques.

2 At the time of writing, both French ecotrons are online, but not all of their features are fully operational.

3 These interviews are a subset of a wider survey of research agendas pursued by French scientists $(n=$ 40) working in biodiversity related fields (see Granjou \& Alpin 2015).

4 Granjou C \& Walker J (2014) Genealogies of the Ecotron. Synthetic Biospheres and Promissory Research Infrastructures, Trends in Environmental Research Seminar Series, Faculty of Science, University of Technology Sydney, 6 August 2014.

5 This is one reason why CNRS committed funds earmarked for the TGIR department rather than drawing down those from the ecology division.

6 The historian of ecology Donald Worster (1994 [1977]), categorizes ecosystems ecology as an "imperialist" form of ecological knowledge linked to technocratic objectives such as efficiency, exploitation and control, in contrast to the "arcadian" type of ecological knowledge which seeks harmony with nature.

7 According to Brian McGill's blog: "the glass blocked ultra-violet light which led to most of the pollinators congregating near the glass boundaries and dying (and the humans having to do a lot of hand pollination). The rainforest, unlike real rainforests, accumulated enormous amounts of leaf litter due to missing microbes (and then things jump started and normal high levels of litter decay are now occurring (we still haven't figured out exactly why). The coral reef crashed and burned for reasons that are still being worked out. The trees were not exposed to wind with interesting implications for growth forms and wood density. An invasive species of ant that snuck in through the soil obliterated much of the intended insect community" (Available at: https://dynamicecology.wordpress.com/2014/03/11/ in-praise-of-a-novel-risky-prediction-biosphere-2/, accessed: 30.5.2014). 
8 See for example the TraitBank project, which aims re-integrate the classification of biodiversity according to the functional traits of organisms. Traits are variously defined depending ecological specialties, "but essentially concern species' properties that affect individual fitness and govern species' impacts and responses to their environment.". TraitNet aims to facilitate integration and synthesis of ecological disciplines around the recording and stocking of traits (http://traitnet.ecoinformatics.org/, accessed: 23.8.2016)

9 The French ecotrons are part of two European programs for the design and construction of experimental infrastructures for systems ecology: Infrastructure for Analysis and Experimentation on Ecosystems (AnaEE) and Integrated Infrastructure Initiative (ExpeER ) program).

10 http://www.cnrs.fr/inee/outils/ecotrons.htm; http://www.ecotron.cnrs.fr/index.php/en/; http://www. foljuif.ens.fr/; http://fr.wikipedia.org/wiki/\%C3\%89cotron. (Accessed: 30.5.2014).

11 For instance flux towers, which measure $\mathrm{CO} 2$ concentration and temperature at the bottom and at the top of the studied trees; some outdoor devices also increase temperature and $\mathrm{CO} 2$ concentration locally in the air.

12 Quotations in this paragraph are from: http://www.ecotron.cnrs.fr/index.php/en/context/scientificchallenges (Accessed: 15.5.2014).

13 The view that human societies will "utilize" the "benefits" of global warming, such as accelerated plant growth due to rising atmospheric concentration of $\mathrm{CO} 2$, or the warming of cold regions is expressed in Montpellier ecotron website (accessed: 1.5.2014).

14 Proteomics is the large-scale study of proteins. 